\title{
Condomínios Industriais em Atibaia-SP: o espaço mudando a indústria e as políticas territoriais
}

Les condominiums industriels à Atibaia-(SP): l'espace change l'industrie et les politiques territoriales

Industrial Condominiums in Atibaia-SP: the space changing the Industry and the territorial policies

Condominios Industriales en Atibaia-SP: El espacio cambiando la industria y las políticas territoriales

\section{Auro Aparecido Mendes}

\section{(2) OpenEdition}

\section{Journals}

Edição electrónica

URL: http://journals.openedition.org/espacoeconomia/807

DOI: 10.4000/espacoeconomia.807

ISSN: 2317-7837

Editora

Núcleo de Pesquisa Espaço \& Economia

Refêrencia eletrónica

Auro Aparecido Mendes, « Condomínios Industriais em Atibaia-SP: o espaço mudando a indústria e as políticas territoriais », Espaço e Economia [Online], 4 | 2014, posto online no dia 11 setembro 2014, consultado o 15 novembro 2019. URL : http://journals.openedition.org/espacoeconomia/807 ; DOI : 10.4000/espacoeconomia.807

Este documento foi criado de forma automática no dia 15 novembro 2019.

(C) NUPEE 


\title{
Condomínios Industriais em Atibaia- $\mathrm{SP}$ : o espaço mudando a indústria e as políticas territoriais
}

\author{
Les condominiums industriels à Atibaia-(SP): l'espace change l'industrie et les \\ politiques territoriales \\ Industrial Condominiums in Atibaia-SP: the space changing the Industry and \\ the territorial policies \\ Condominios Industriales en Atibaia-SP: El espacio cambiando la industria y las \\ políticas territoriales
}

Auro Aparecido Mendes

\section{Introdução}

1 Espaços dotados de capacitações técnicas, logísticas e de serviços na forma de condomínios industriais e centros empresariais tem possibilitado a integração entre empresas dos mais variados ramos ou setores da atividade econômica que, no passado, encontravam-se dispersos geograficamente.

O condomínio industrial ou empresarial compreende um parque de fornecedores diretos, comércio e serviços localizados num mesmo espaço. A existência de fornecedores e outras atividades de apoio atraem novos investimentos e empreendimentos.

Os condomínios industriais e empresariais existem tanto em regiões metropolitanas quanto em cidades médias, abarcando uma grande variedade de gêneros industriais, podendo ou não ser especializados em um ramo produtivo.

Com base no que foi exposto, a presente pesquisa teve por fito pesquisar a crescente implantação de condomínios industriais no município de Atibaia SP.

5 Os condomínios industriais encontram-se localizado a $35 \mathrm{~km}$ do "Vale do Silício Brasileiro" (Região Metropolitana de Campinas), próximo de importantes municípios 
como São José dos Campos, Rio de Janeiro, região da grande São Paulo e sul do estado de Minas Gerais; assumindo um papel de extrema relevância no desenvolvimento da região metropolitana de Campinas, especialmente. A presença de universidades e centros de pesquisa de referência internacional confere à Campinas uma posição de destaque entre os centros de excelência de alta tecnologia.

6 A cidade de Campinas desponta pela concentração de instituições de pesquisa e desenvolvimento tecnológico, como por exemplos, o Centro de Pesquisa e Desenvolvimento (CPqD) da Telebrás, o Instituto Nacional de Tecnologia da Informação (ITI) e as unidades de pesquisa da Embrapa. Acrescentam-se, também, as universidades Puccamp e Unicamp.

7 Estas instituições tornam-se ainda mais conceituadas por atuarem junto às grandes corporações. As indústrias instaladas no condomínio encontram profissionais qualificados no município, capazes de suprir as necessidades tecnológicas e de pesquisa de cada unidade produtiva. Em contrapartida, a parceria entre universidades, institutos de pesquisa e empresa garante a continuidade da formação de bons profissionais, o desenvolvimento de tecnologia de ponta, reciclagem e atualizações permanentes dos profissionais engajados nas empresas.

8 Considerando a existência desse "meio técnico-científico-informacional", surgem novas formas espaciais, entre elas os condomínios industriais e empresariais. Se no passado a indústria organizava o espaço em função de suas instalações e de suas demandas, atualmente, é o espaço quem organiza as atividades econômicas. Se no passado, as indústrias eram integradas, nos dias atuais, é o espaço que se encontra integrado.

o espaço, cada vez mais conectado, articulado e integrado, ocupa, atualmente, o papel desempenhado pela indústria no passado. Portanto, a equação não é mais indústria/ espaço; mas sim, espaço/indústria. Trata-se da produção do espaço (na forma de Condomínios Industriais), resultado da iniciativa privada (agente social), determinando as atividades econômicas.

10 Cabe, entretanto, esclarecer que o espaço nesta pesquisa não é considerado ator social, sujeito social ou protagonista; mas uma produção social. Uma produção social que abriga, que aloja, que oferece guarida às instalações empresariais e industriais.

Obviamente, que nesta nova lógica espacial, o papel do Estado também muda. Ele deixa de ser o promotor ou indutor do desenvolvimento territorial para ser um facilitador (através de concessões, incentivos fiscais, infraestruturas, etc.) da valorização e, porque não dizer, da especulação imobiliária desses espaços produtivos por agentes públicos e privados.

Assim sendo, as vantagens competitivas ou comparativas dinâmicas existentes nestes condomínios industriais e empresariais são decorrências dessa nova relação espaço/ indústria.

13 Com base nessas considerações iniciais, o presente trabalho encontra-se estruturado da seguinte forma: na seção 1 são apresentados os principais aportes teóricos que fundamentaram a pesquisa; na seção 2 é feita uma breve contextualização econômica da Região Metropolitana de Campinas, destacando os principais aspectos para a instalação de indústrias intensivas em tecnologia e para a implantação de condomínios industriais e empresariais. A seção 3 consiste na análise detalhada das condições gerais para a implantação de condomínios industriais em Atibaia SP e das principais políticas públicas adotadas. 
Por último, com base no exemplo empírico é feita uma reflexão sobre a nova configuração do espaço industrial.

\section{Fundamentação Teórica}

15 Não são todos os lugares que disponibilizam desses novos fatores locacionais (mão-deobra qualificada, existência de universidades e institutos de pesquisa, proximidade de aeroportos, entre outros) que geram uma nova paisagem empresarial e industrial completamente diferente dos antigos complexos fabris. Verifica-se, assim, que nas organizações produtivas pretéritas, o espaço encontrava-se subordinado aos interesses da indústria, funcionando como "palco", "plataforma de produção", ou ainda, como simulacro para a reprodução do grande capital.

Atualmente a função indústria-espaço encontra-se invertida o espaço integrado organiza as atividades produtivas de forma a permitir um aumento de sua rentabilidade.

17 Nota-se que nesta nova dinâmica tecnológica o conhecimento, o aprendizado, a troca de informações torna-se um ativo fundamental da competição, impondo novas formas de organização e de interação entre as empresas. Tais relações entre empresas ou interindustriais ("linkages") podem ser tanto materiais, tangíveis (matérias-primas naturais, mercadorias, por exemplos) como imateriais ou intangíveis (troca de informações ou conhecimento).

18 Nesta onda de inovações tecnológicas, presenciam-se mudanças radicais em várias esferas que vão desde o refinamento tecnológico dos equipamentos empregados, per si, até a qualificação da mão-de-obra e os princípios ordenadores da organização do trabalho e da produção.

19 Diniz (2001, p. 10), analisando o papel da inovação no desenvolvimento regional ou local ressalta que na sociedade atual dominada pelo conhecimento as vantagens comparativas estáticas ou ricardianas perdem importância e emergem novas vantagens construídas e criadas no conhecimento e na inovação.

20 A competitividade torna-se, assim, mais acirrada e o processo de inovação, de conhecimento e de aprendizagem abrem no território "janelas de oportunidade" (Dosi,

21 1984) que são "janelas locacionais" (Storper e Walker, 1989).

22 O espaço mais seletivo, acaba restringindo a implantação de certas atividades ou ramos produtivos a serem implantados nos condomínios industriais ou centros empresariais.

23 Asheim e Cooke (1997) identificam a relevância dos seguintes aspectos facilitadores do processo de inovação na dimensão local:

- presença de capital humano, interações entre firmas, escolas, universidades, centros de treinamento;

- redes formais e informais de negócios e troca de informações;

- sinergia e ambiente inovativo de cultura compartilhada;

- presença de instituições de suporte empresarial.

Para os autores mencionados o processo de aprendizagem é predominantemente interativo e socialmente imerso no contexto institucional e cultural.

Conhecimento e aprendizagem são complementares e específicos na composição de muitas empresas e territórios e na relação espaço / indústria. o entendimento, a 
compreensão de como circulam tais conhecimentos na cadeia produtiva, a fertilização cruzada de ideias, suas sinergias, suas interações internas (entre os diferentes departamentos da empresa e seus fornecedores e parceiros próximos) e externas (com universidades, institutos de pesquisa, consultores, clientes, usuários, entre outros) consistem em importantes atributos ou recursos espaciais. O espaço em si é gerador de coordenação, estabelecendo normas e diretrizes que irão permear a organização e o desenvolvimento das atividades econômicas.

Para Pecqueur e Zimmermann (2005, p. 96) a proximidade geográfica concorre para a produção de externalidades favorecendo a inovação. Conforme os autores, o contato face a face se alimenta da história comum do conjunto de atores. Esta especificidade da coordenação de proximidade espacial gera laços de confianças nas relações face a face e funcionam como um elemento facilitador na ancoragem territorial.

28 A proximidade geográfica enseja um processo de aprendizado que necessita para a sua materialização e sustentação instituições que possibilitem um upgrading de suas capacidades produtivas, inovativas, habilidades e competências.

O espaço impregnado pelas informações, conhecimentos e inovações cria uma "atmosfera empresarial e industrial" onde todos os atores envolvidos passam a desfrutar da eficiência coletiva gerada.

\section{Condomínios Industriais e Empresariais na Região Metropolitana de Campinas e Entorno:}

Se não fosse a importância dos recursos espaciais construídos historicamente sob a forma de vantagens competitivas do / no lugar; jamais as empresas nacionais e estrangeiras estariam instaladas na Região Metropolitana de Campinas.

Historicamente, a cidade de Campinas foi transformando-se numa cidade produtora de bens materiais em uma região metropolitana lócus da circulação e de consumo de bens simbólicos e informacionais.

Campinas foi criada em 1774 e a sua economia nesta época era baseada no plantio de cana e na produção do açúcar. Comparativamente a produção de cana-de- açúcar na região era inferior ao volume de exportações de outras regiões do país, como da Região Nordeste, por exemplo. Rapidamente o cultivo do café despontou e assumiu, ainda naquele século, o primeiro lugar na produção regional.

3 Em 1868, com a inauguração da Companhia Paulista de Estradas de Ferro, ligando Campinas a Jundiaí e, posteriormente, ligando-se a capital e ao Porto de Santos, Campinas passou a ser o maior entroncamento ferroviário do Império.

As formas pretéritas de organização do espaço deixam "fixos" que segundo Santos (1996) constituem "rugosidades" que interagem com as formas atuais. Na cidade, verifica-se, portanto, conforme o autor, a "complementaridade de atividades e de funções".

A economia cafeeira desenvolveu-se sem inibir a diversificação de outras atividades econômicas relacionadas com a agropecuária e a agroindústria.

No período de 1930-1960, a economia de Campinas era marcadamente industrial e o seu comércio bastante diversificado, consolidando-se como o mais importante centro regional do estado de São Paulo. 

econômica, realçando, cada vez mais, a sua posição de destaque no processo de atração de novos investimentos, de mobilidade populacional e de concentração industrial no espaço urbano paulista.

Na década de 1970, a região de Campinas foi a que mais recebeu investimentos através do processo de desconcentração industrial ocorrido a partir da Região Metropolitana de São Paulo e com a instalação de grandes e importantes empresas estrangeiras (Mendes, 1991).

$\mathrm{O}$ processo de desconcentração industrial rumo ao interior do estado resultou da combinação de uma série de políticas, como está sendo elucidado: a) que proibiram o implante de novas indústrias na Região Metropolitana de São Paulo (políticas restritivas), b) políticas que promoveram o deslocamento de indústrias para outras regiões do estado (políticas promotoras ou diretivas), e c) políticas atrativas municipais. Entretanto, este processo de desconcentração da atividade fabril não atinge todas as cidades do interior igualmente, mas, aquelas que possuem alguma vantagem competitiva.

Conforme Lencioni (1994, p. 207):

A reestruturação da metrópole de São Paulo, produto dos processos de concentração e centralização do capital, se traduz num fenômeno sócio-espacial novo, criação e reiteração de uma região metropolitana mais complexa, fragmentada e hierarquizada, em que a conurbação de cidades, o crescimento relativamente menor de algumas ou, exacerbado de outras - como, por exemplo, o grande crescimento de Campinas -, não significam processos autônomos de metropolização. Ao contrário, são manifestações constitutivas da expansão do espaço metropolitano paulista, que se configura numa "macrometrópole" que é reforçada e, não negada, pela dispersão de suas atividades.

41 A Região Metropolitana de Campinas é considerada, pela Agência de Inovação da UNICAMP, como uma das principais áreas de inovação da América Latina. Juntamente com São José dos Campos e Litoral, forma um macro-eixo de desenvolvimento técnicocientífico-informacional.

É neste contexto, neste ambiente industrial, neste entorno inovador, nesta "região inteligente", no Vale do Silício Brasileiro, que os Condomínios Industriais e Centros Empresariais começam a surgir, a partir da década de 1990, na Região Metropolitana de Campinas.

43 Trata-se de uma nova configuração espacial, completamente diferente das antigas paisagens fabris e dos tradicionais complexos industriais. São espaços totalmente integrados, "logisticamente ideais", dotados de alta tecnologia, "ambientalmente corretos" e onde os serviços são compartilhados entre as empresas ou indústrias instaladas. Nestes espaços, as empresas selecionadas desfrutam das vantagens competitivas existentes. Como já foi ressaltado, anteriormente, a participação do Estado em relação a estes novos formatos espaciais deixa de ser de indutor para ser de facilitador.

\section{Condomínios Industriais em Atibaia: Vantagens Locacionais e Políticas Públicas}

Os Condomínios Industriais em Atibaia encontram-se estrategicamente localizado a $60 \mathrm{~km}$ de São Paulo e a $35 \mathrm{~km}$ de Campinas, no centro de importante malha viária interligada às 
principais rodovias estaduais e federais, atingindo com rapidez os mais importantes centros consumidores do país.

A Rodovia D. Pedro I, além de ser o Corredor de Exportação mais importante do país, é o centro da malha viária, interligando os dois maiores aeroportos do Brasil: Guarulhos (Cumbica) e Campinas (Viracopos).

Os Condomínios estão implantados em Atibaia e região estão no centro dos quatro maiores mercados da América Latina:

- a cidade de São Paulo e sua área metropolitana;

- o interior do estado de São Paulo;

- o Vale do Paraíba e o Rio de Janeiro;

- o sul do estado de Minas Gerais.

desenvolvimento econômico de Atibaia encontra-se associado à chegada de imigrantes italianos, espanhóis e japoneses que vieram em busca de oportunidades de trabalho e de sobrevivência. Além da excelente localização e recursos paisagísticos, a Estância de Atibaia conta com ótima infraestrutura hoteleira, bons restaurantes, comércio diversificado e estrutura turística com parques, museus e clubes. Rica em biodiversidade animal e vegetal, Atibaia é considerada a cidade dos frutos e das flores, cercada por montanhas, local ideal para a prática de esportes como voos livres que contempla uma das mais belas paisagens do país.

Conhecida nacionalmente como Suíça Brasileira, Atibaia, com uma população de 111.000 habitantes (segundo o Censo Demográfico, IBGE, 2000) tem o $2^{\circ}$ melhor clima do mundo, segundo a classificação da Organização Mundial da Saúde e o maior PIB do Brasil.

49 A história de Atibaia está relacionada à atuação dos bandeirantes, desbravadores no século XVII que saíam em pequenas comitivas para explorar as terras virgens, em busca de índios e minerais preciosos. A maioria das expedições partia de São Paulo rumo ao caminho das "Minas Gerais". Tratava-se de uma viagem longa e árdua que requeria muitas paradas para descanso e reabastecimento. A primeira parada neste percurso, ainda nas proximidades de São Paulo ficava na colina banhada por um rio que os índios chamavam de "tubaia" ou "atubaia" que significa "água agradável ao paladar".

Considerando a qualidade de vida no município e a sua excelente localização que os condomínios industriais foram construídos e administrados por uma holding de capitais locais. Se no passado o espaço era identificado pelas indústrias nele instaladas, atualmente, as indústrias e os condomínios industriais procuram ter a sua imagem associada ao espaço.

51 A holding mencionada é responsável pela edificação, incorporação, consultoria e administração de Condomínios Industriais e Empresariais. Trata-se de um dos maiores complexos empresariais da América Latina.

De acordo com os seus administradores os principais fatores locacionais responsáveis pela implantação dos condomínios em Atibaia foram:

- Localização/ facilidades de acesso

- Incentivos fiscais

- Clima/qualidade de vida

- Mão-de-obra qualificada

53 Observa-se que, embora existam alguns clássicos fatores locacionais mencionados, os mesmos não foram determinantes. Determinante é a produção do espaço sob a forma de 
condomínio que passa a coordenar as empresas e a indústrias nele instaladas. Tais espaços moldam uma nova fábrica, uma nova empresa, cada vez mais competitiva $\mathrm{e}$ inteligente.

Com localização privilegiada os Condomínios Industriais desse grupo empresarial reúnem instrumentos de estruturas logísticas fundamentais para que as empresas concentrem- se em seus produtos e mercados.

No Condomínio a empresa encontra infraestrutura pronta para uso, não precisando preocupar-se com absolutamente nenhum item que não seja específico do seu próprio negócio. A empresa diminui, dessa maneira, o esforço e o tempo necessários para suas atividades. Todos os serviços complementares estão instalados e disponíveis para uso imediato.

o condomínio industrial é um prédio inteligente que conta com todos os avanços tecnológicos e serviços que uma empresa precisa, tais como:

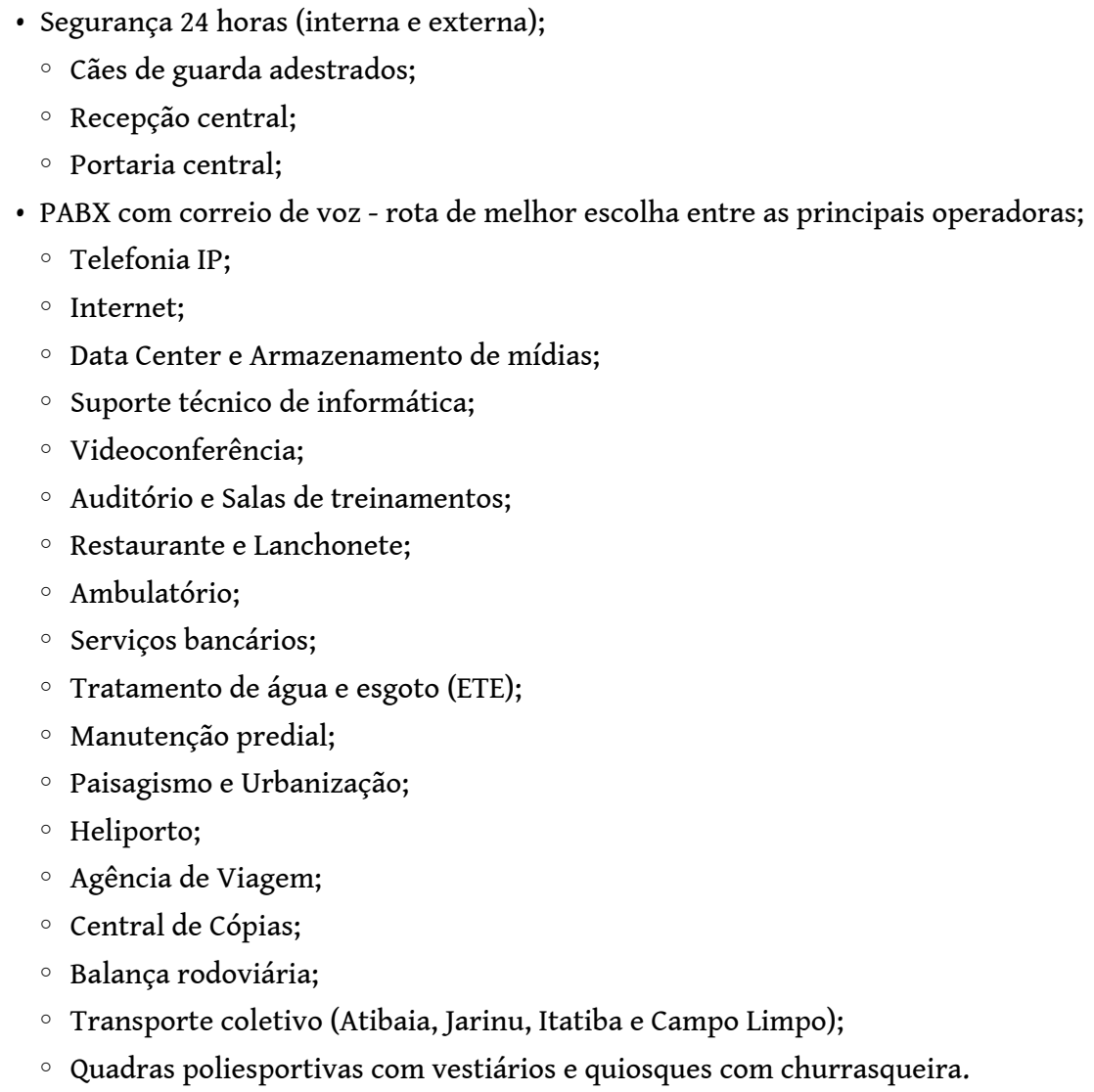

Trata-se, portanto, de uma nova relação espaço/indústria, permeada por aportes tecnológicos, informacionais e de serviços que permitem a eficiência coletiva de todas as empresas instaladas.

59 Os administradores do condomínio industrial consideram a Prefeitura Municipal de Atibaia uma parceira, uma facilitadora, aprovando os processos de implantação das empresas no condomínio. Na verdade, a atuação dos poderes públicos municipais consiste na Lei de Incentivos Fiscais (isenção de IPTU por aproximadamente 10 anos) e redução de ICMS, principalmente. 
60 O poder público municipal, funcionando como um facilitador, como um parceiro desse processo de desenvolvimento econômico, está propondo a criação de uma zona especial de interesse para o desenvolvimento econômico do município, que inclui incentivos fiscais para a instalação de empresas de médio e grande porte. A Prefeitura pretende adequar a legislação à criação de um eixo de desenvolvimento econômico, com atenção especial à atividade logística de distribuição.

61 A criação do eixo estabelecerá uma legislação que determine uma faixa de 700 metros a partir dos dois lados da Rodovia D. Pedro I que passe a ser de interesse para estabelecimentos e implantação de empreendimentos (empresas e indústrias) de médio a grande porte. Em outras palavras, significa dizer que em toda a extensão da Rodovia D. Pedro I que corta o município só serão aprovados grandes e médios empreendimentos, sem possibilidade de aprovação, por exemplos, de loteamentos residenciais.

62 Contando com todas essas vantagens competitivas e como o apoio de políticas públicas o que se verifica entre os municípios de Atibaia e Campinas é um grande número de condomínios industriais e empresariais em funcionamento e outros sendo construídos, selecionando as fábricas e as empresas condôminas.

Esse espaço integrado obviamente não é encontrado em qualquer lugar. Na verdade o espaço industrial mudou, tornando-se mais inteligente, com base em outra lógica produtiva, muito mais ágil e eficiente. Dessa forma, esse novo espaço seletivo e exigente tem promovido uma verdadeira reengenharia nas indústrias e nas empresas.

\section{Considerações Finais}

Se nas décadas de 1970 e 1980 o Estado em suas diferentes esferas de atuação induziu o processo de desconcentração industrial ocorrido no estado de São Paulo, atualmente, são as grandes empresas incorporadoras, de capitais privados, que tem, através de condomínios empresariais, comandado tal processo.

\section{Se no passado o espaço era fragmentado agora ele é integrado.}

Antes a integração era possível; atualmente, a integração é real, determinada pela forma como o espaço está organizado.

Assim sendo, a estrutura produtiva do município de Atibaia mudou. Existe uma nova forma, uma nova função, um novo conteúdo, engendrado pela dinâmica sócio-espacial e pela reestruturação econômica em curso, cujas tensões e as contradições estão sendo manifestadas.

68 Por meio da iniciativa privada (agente social), da privatização do território, a produção do espaço, sob a forma de condomínios industriais, alterou profundamente a Estância Turística de Atibaia que, antes da construção dos condomínios industriais, era conhecida pelos recursos paisagísticos e pela plantação de mandiocas, flores e pêssegos, principalmente.

A imagem da cidade hoje está atrelada, sobretudo, aos condomínios industriais.

Como a relação agora não é mais indústria/ espaço, mas sim, espaço/ indústria, a atuação do Estado foi modificada. A relação não é mais Estado / espaço, mas sim, espaço/Estado.

Como foi analisado, tal desenvolvimento econômico conta com o apoio e incentivos do poder local, criando as condições para a produção e a reprodução do capital. 

espaço construído (condomínios industriais). A valorização se dá no, do e através do espaço. investirem em novos condomínios industriais, como acontece com os condomínios em execução em Atibaia, Jarinu e Itatiba.

O espaço tem comandado, dessa maneira, o desenvolvimento econômico endógeno. Não é qualquer indústria que se implanta em Atibaia. Não é qualquer indústria que se instala no condomínio industrial.

Os condomínios industriais, principalmente no estudo de caso realizado, revela que o espaço não é desarticulado ou fragmentado. 0 espaço articulado e integrado tornou-se, logisticamente, inteligente, ágil, seletivo e ambientalmente exigente e correto.

Por fim, vale enfatizar que essa nova organização das atividades econômicas só é possível quando o espaço determina a indústria.

\section{BIBLIOGRAFIA}

ASHEIM, B.T.; COOKE, P. Localized innovation networks in global economy: a comparative analysis of endogenous and exogenous regional development approaches. In: IGU COMISSION ON THE ORGANISATION OF INDUSTRIAL SPACE REDIDENTIAL CONFERENCE. Gotthenburg, Sweden, August, 1997.

DINIZ, C.C. Globalização, Escalas Territoriais e Políticas Tecnológicas Regionalizadas no Brasil. Belo Horizonte: UFM/CEDEPLAR, 2001 (Texto para discussão, 168).

DOSI, G. Technical change and industrial transformation. London: Macmillan, 1984.

LENCIONI, S. Reestruturação Urbano-Industrial no Estado de São Paulo: a região da metrópole desconcentrada. In: Santos, M. et al. (Org). Território: Globalização e Fragmentação. São Paulo: Hucitec/ANPUR, 1994.

MENDES, A.A. Implantação Industrial em Sumaré: Origens, Agentes e Efeitos. Contribuição ao estudo da interiorização da indústria no Estado de São Paulo. Rio Claro: Universidade Estadual Paulista, UNESP, 1991 ( Dissertação de Mestrado).

PECQUEUR, B.; ZIMMERMANN, J.B. Fundamentos e uma economia da proximidade. In: DINIZ, C.C.; LEMOS, M.B. (Org.). Economia e Território. Belo Horizonte: Editora UFMG, 2005.

SANTOS, M. A natureza do espaço. Técnica e tempo. Razão e emoção. São Paulo: Hucitec, 1996. STORPER, M,; WALKER, D. The capitalismo imperative: territory, technology and industrial growth. New York: Basil Blackwell, 1989. 


\section{RESUMOS}

$\mathrm{O}$ alcance espacial do sistema produtivo tornou-se global. Fundado sobre vantagens competitivas, o momento atual engendra novas relações produtivas e territoriais. Nossa pesquisa analisa a emergência de condomínios industriais em Atibaia-São Paulo (SP) e suas ligações com a produção e a reprodução do capital. Cada vez mais conectado e integrado, o espaço ocupa atualmente o papel outrora jogado pela indústria. Nossa pesquisa mostrou que os condomínios trouxeram profundas mudanças no que concerne à valorização do espaço, dinamizando o desenvolvimento local e, por conseguinte, as políticas territoriais.

La portée spatiale du système productif est devenue globale. Fondée sur des avantages competitives, le moment actuel engendre des nouveaux rapports productifs et territoriaux. Notre recherche analyse l'émergence de condominiums industriels à Atibaia-São Paulo (SP) et leurs liaisons avec la production et la reproduction du capital. Chaque fois plus conecté et integré, l'espace occupe actuellement le rôle occupé jadis par l'industrie. Notre recherche a montré que les condominiuns ont apporté des changements profondes en ce qui concerne à la valorisation de l'espace, en dynamisant le développement local et, par conséquent, les politiques territoriales.

The spatial range of the productive system has become global, basing itself on competitive advantages, generating new productive and territorial relationships. The main objective of the research was to analyze the rise of Industrial Condominiums in Atibaia/SP e how the general conditions to the production and reproduction of the capital occurred. The space, more and more connected, articulated and integrated, occupies, nowadays, the role that the industry did in the past. Therefore, the equation is not even more industry/space, but space/industry. The research evidenced that the condominiums have brought deep transformations in/of and through the space valuation, streamlining the local development and causing, thus, changes in territorial policies.

La gama espacial del sistema de producción está globalizado, basándose en una ventaja competitiva mediante la generación de nuevas relaciones productivas y territoriales. El objetivo general del estudio fue analizar la emergencia de Condominios Industriales en Atibaia SP y las condiciones generales para la producción y reproducción del capital . El espacio, cada vez más conectado, integrado y articulado, en la actualidad ocupa el papel desempeñado por la industria en el pasado. Nuestra investigación mostró que los condominios se han producido profundos cambios en el espacio de valoración, estimulando el desarrollo local y causando por lo tanto los cambios en las políticas territoriales.

\section{ÍNDICE}

Mots-clés: condominiums industriels, Atibaia-SP, espace, politiques territoriales, capital Palavras-chave: condomínios industriais, Atibaia-SP, espaço, políticas territoriais, capital Palabras claves: condomínios industriales, Atibaia-SP, espacio, políticas territoriales, capital Keywords: industrial condominiums, Atibaia-SP, space, territorial policies, capital 
AUTOR

AURO APARECIDO MENDES

Professor Adjunto do Departamento de Geografia-IGCE-UNESP-Rio Claro auromendes@uol.com.br 